\title{
AQUIFER DIAGNOSIS FOR SAN JOSE CHIAPA REGION, MEXICO
}

\author{
MARGARITA TEUTLI, ANDRES SANCHEZ \& GABRIELA VIDAL \\ Department of Engineering and Technology, Benemerita Universidad Autonoma De Puebla, Mexico
}

\begin{abstract}
An aquifer diagnosis of San José Chiapa, Puebla and 7 surrounding towns was performed to set up a reference for water quality in towns nearby Audi the car maker factory. For this study 38 water samples were collected and characterized for 20 physicochemical parameters, obtained data were compared with two reference standards: drinking water and irrigation. In reference to the Drinking Water Mexican Standards it was found that $37 \%$ of the samples exceed the upper limit of $\mathrm{pH}(8.5)$, nitrite in $100 \%$ (limit value $0.05 \mathrm{ppm}$ ), cadmium $92 \%$ (limit value $0.005 \mathrm{ppm}$ ), and lead $79 \%$ (limit value $0.01 \mathrm{ppm}$ ). Otherwise, irrigation standards account for ionic content interactions, so far Sodium Accumulation Rate (SAR) represents a low risk for soil degradation by itself since 3\% of the samples classify in the low-medium risk; but in presence of alkalinity adjusted SAR displaces $95 \%$ of the samples to a high risk classification, which means a threat for soil structure and permeability; a degree of restriction in water use can inferred from SAR-Electrical Conductivity (EC) data, results indicate a high restriction for $44 \%$ of the samples, and a low to moderate restriction in $32 \%$ of the samples. Exchangeable Sodium Percentage (ESP) accounts for $\mathrm{Na}, \mathrm{Ca}, \mathrm{Mg}$, and $\mathrm{K}$ interactions, results indicate that $32 \%$ of the samples are facing expansion risk, and $13 \%$ face rupture of the soil matrix. Under Alkalimetric Co-efficient or Scott Index (ACSI) $42 \%$ of samples fall in a bad-mediocre quality. Interactions of ions under irrigation standards was confirmed by applying a Pearson's correlation statistical analysis, in which it is found that correlation involving $\mathrm{EC}, \mathrm{Cl}, \mathrm{SO} 4, \mathrm{Na}, \mathrm{K}, \mathrm{Ca}, \mathrm{Mg}$ fall in the range of strong to very strong (0.6-1.0), all these ions are involved in estimation of SAR, SAR ADJ, ESP and ACSI.

Keywords: aquifer diagnosis, irrigation water, industrialization, environmental risk.
\end{abstract}

\section{INTRODUCTION}

San José Chiapa is a municipality of Puebla State, México, which has a surface area of $177 \mathrm{~km}^{2}$, and according to the last count [1], it had a population density of 46 habitants-km². Some years ago, land farming was the main activity at this site, but settlement of the car maker Audi has modified usual activities into the ones associated to the industrialization process which is undergoing at that place. Urbanization has been done in accelerated steps including construction of buildings, freeways, housing, universities etc.

Official information about San José Chiapa landscape has been published by Mexican institutions like National Institute of Statistics and Geography (INEGI) [2], and the Water Bureau (CONAGUA) [3], in their reports it is mentioned that San José Chiapa geological structure is about $40 \%$ of calcareous consolidated materials having high permeability. Also, hydraulic resources are scarce, most of them are perennial streams, and there is presence of a shallow aquifer in which groundwater has long residence time allowing for calcareous material dissolution [4]; therefore, water from wells cannot be used for human consumption without treatment.

From the above arguments, it is obvious the necessity of doing a groundwater evaluation for assessing its quality at the region. In this sense, this work presents an approach to a preliminary water diagnosis using 38 sampling points, 23 at the San José Chiapa zone and 15 at other nearby places. 


\section{METHODOLOGY}

\subsection{Study area}

Sample collection was done in 2 periods (years 2015 and 2016). In Fig. 1 it is shown a site map built using INEGI geographical information, sampling points are shown in two kind of markers green stars for 2015 and dotted yellow squares for 2016. As it can be observed the collection of samples was done in a valley located between the 2300-2500 meters above sea level. Also, in this valley most of the water bodies and streams fall into the perennial kind.

\subsection{Determination of water physicochemical parameters}

Water samples were collected in clean vessels, stored in ice and transported to the Environmental Engineering Laboratory, for characterization of the following physicochemical parameters: a) $\mathrm{pH}$ using a CL10 conductronic pH-meter; b) electrical conductivity (EC) using a C8 conductronic conductivity meter; c) chloride (Cl); phenolphthalein $(\mathrm{AlkPH})$ and methyl orange (AlkM) alkalinities; Calcium Hardness ( $\mathrm{HCa})$ and Total Hardness $(\mathrm{TH})$ determination by gravimetric techniques; d) sulphate $\left(\mathrm{SO}_{4}\right)$, nitrite $\left(\mathrm{NO}_{2}\right)$, nitrate $\left(\mathrm{NO}_{3}\right)$, phosphate $\left(\mathrm{PO}_{4}\right)$, fluoride $(\mathrm{F})$ were determined with visual spectrophotometer HACH DR 2500 and $\mathrm{HACH}$ reagents; e) detection of Sodium (Na), Calcium (Ca) Potassium (K), Iron (Fe), Magnesium (Mg), Manganese (Mn), Lead ( $\mathrm{Pb}$ ) and Cadmium (Cd) was done with atomic absorption spectrophotometer GBC932. Analytical data was statistically analysed using the minitab V1.7 statistical software.

\subsection{Estimation of water quality indexes}

Once the analytical results are obtained, they are compared with the standards for drinking water and irrigation uses [5]-[8], quality indexes are based on the relationships between physicochemical parameters, for their assessment is considered the following information: $p H$ - Optimal range for irrigation is $7-8$, but for drinking water the range is a little wider 6.5-8.5.

Electrical conductivity (EC, $\left.\mu \mathrm{S} \mathrm{cm}^{-1}\right)$. This parameter is not restricted in drinking water but it represents a degree of salinity risk as follows: 0-250 low, 250-750 medium, 750-2250 high, $>2250$ very high.

Sodium Accumulation Rate (SAR, meq $^{-1}$ ). This index considers interactions $\mathrm{Na}-\mathrm{Ca}-\mathrm{Mg}$, since sodium exerts influence onto soil permeability and its presence enables soil degradation. It is calculated by using the eqn (1):

$$
S A R=\frac{|N a|}{\sqrt{\frac{|C a|+|M g|}{2}}}
$$

In this equation metal concentrations should be expressed in meq $\mathrm{l}^{-1}$. Salinity risk is defined according to the SAR values interval: $0-10=$ low, $10-18=$ medium, $18-26=$ high, $>26=$ very high. If there is presence of carbonate and bicarbonate, these must be accounted and the SAR should be adjusted (SARadj) as follow:

$$
\begin{gathered}
S A R_{a d j}=S A R(1+8.4 p H c) \\
p H c=\left(p K_{2}+p K_{1}\right)+p(|C a|+|M g|)+p A l k
\end{gathered}
$$

where $p H c$ is the theoretical irrigation water $\mathrm{pH}$, when there is presence of calcite $\left(\mathrm{CaCO}_{3}\right)$ in equilibria with atmospheric $\mathrm{CO}_{2}$; otherwise, $\mathrm{pK}_{1}, \mathrm{pK}_{2}$ are the logarithmic expression of 
the equilibrium constants for the $\mathrm{CO}_{3}$ and $\mathrm{HCO}_{3}$ equilibria; $\mathrm{pAlk}$ is calculated with the titrable concentration of $\mathrm{CO}_{3}$ and $\mathrm{HCO}_{3}$.

Use of natural waters for land farming activities can be restricted by a combined criteria based on interactions between salinity (EC) and sodicity (SAR), since the first affects soil production and the second affects soil structural stability [7]. Table 1 shows the assignation of restriction using the combined criteria.

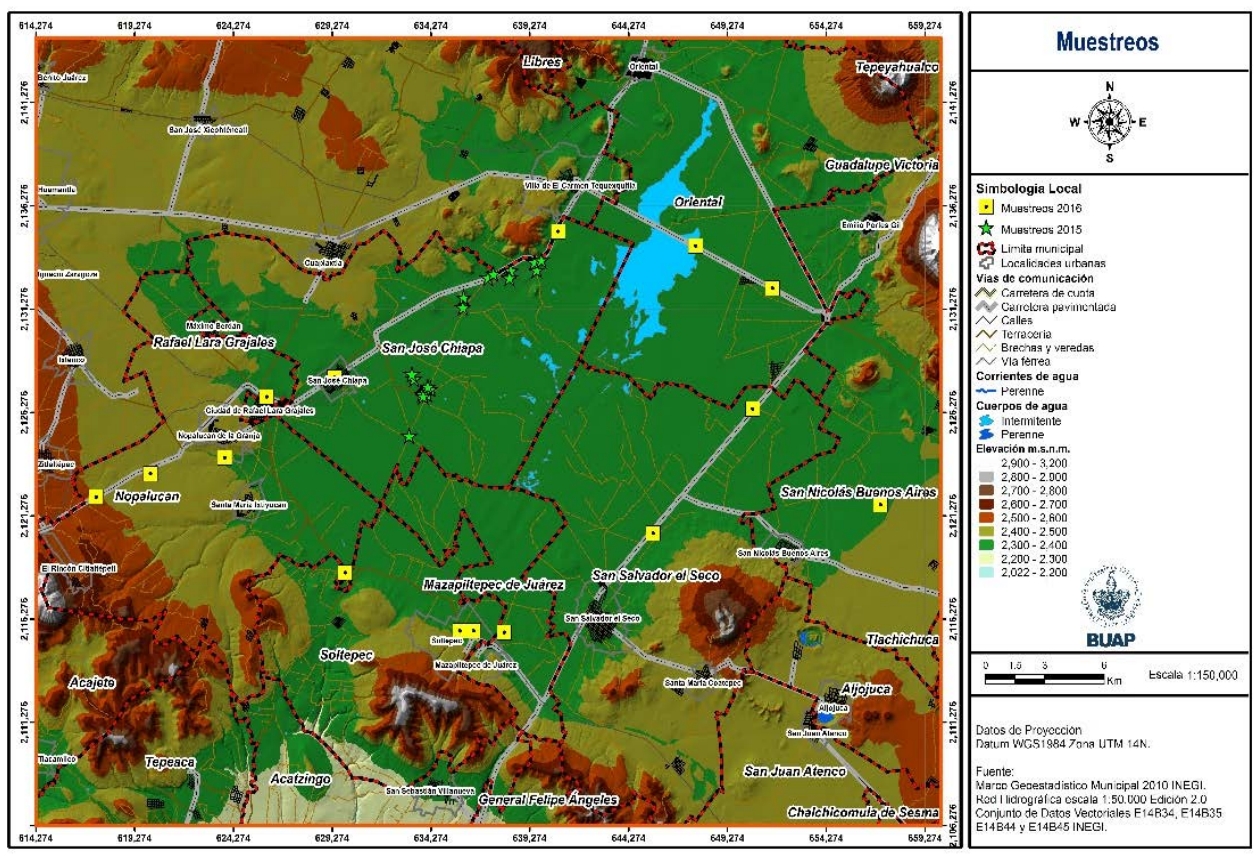

Figure 1: Location of water sampling points.

Table 1: Agronomical quality of natural waters.

\begin{tabular}{|c|c|c|c|}
\hline \multirow{2}{*}{$\begin{array}{c}\text { Potential } \\
\text { problem }\end{array}$} & \multicolumn{3}{|c|}{ Degree of restriction in use } \\
\cline { 2 - 4 } & Null & $\begin{array}{c}\text { Low to } \\
\text { moderate }\end{array}$ & High \\
\cline { 2 - 4 } & \multicolumn{3}{|c|}{$\mathrm{EC}, \mu \mathrm{S} \mathrm{cm}^{-1}$} \\
\hline Salinity $\rightarrow$ & $<700$ & $700-3000$ & $>3000$ \\
\hline Sodicity $\downarrow$ & \multicolumn{3}{|c|}{$\mathrm{EC}, \mu \mathrm{S} \mathrm{cm}^{-1}$} \\
\hline SAR 0-3 & $>700$ & $700-200$ & $<200$ \\
\hline SAR 3-6 & $>1200$ & $1200-300$ & $<300$ \\
\hline SAR 6-12 & $>1900$ & $1900-500$ & $<500$ \\
\hline SAR 12-20 & $>2900$ & $2900-1300$ & $<1300$ \\
\hline SAR 20-40 & $>5000$ & $5000-2900$ & $<2900$ \\
\hline
\end{tabular}


- Alkalimetric Coefficient or Scott Index (ACSI) - This index is based on the relationship between $\mathrm{C}_{1}, \mathrm{SO}_{4}$ and $\mathrm{Na}$, and it is equivalent to the height of water (inches), which after evaporation in a 4 feet depth vegetal field, will left enough alkali to affect normal growth of the most sensitive vegetal species. This index is an indirect measure of toxicity exerted by $\mathrm{NaC}_{1}$ and $\mathrm{Na}_{2} \mathrm{SO}_{4}$. Its value is calculated using the following concentration relationships: i) if $\left[\mathrm{C}_{1}\right]>[\mathrm{Na}]$, $\mathrm{ACSI}=2.040 /\left[\mathrm{C}_{1}\right]$; ii) if $\left[\mathrm{C}_{1}\right]<[\mathrm{Na}]<\left\{\left[\mathrm{C}_{1}\right]+\left[\mathrm{SO}_{4}\right]\right\}$, ACSI $=6.62 /\left\{2.6\left[\mathrm{C}_{1}\right]+[\mathrm{Na}]\right\}$; iii) if $[\mathrm{Na}]>\left\{\left[\mathrm{C}_{1}\right]+\left[\mathrm{SO}_{4}\right]\right\}, \mathrm{ACSI}=662 /\left\{[\mathrm{Na}]-0.2\left[\mathrm{C}_{1}\right]-\left[\mathrm{SO}_{4}\right]\right\}$. Water quality is considered bad if $\mathrm{ACSI}<1.2$; mediocre if $1.2<\mathrm{ACSI}<2.6$; tolerable if $6<\mathrm{ACSI}<18$; and good if ACSI $>18$.

- Exchangeable Sodium Percentage (ESP) - This index considers the Na abundance in respect to the sum of $\mathrm{Na}, \mathrm{Ca}, \mathrm{Mg}$ and $\mathrm{K}$; . This parameter is calculated by the ratio of $[\mathrm{Na}] /\{\{\mathrm{Na}]+[\mathrm{Ca}]+[\mathrm{Mg}]+[\mathrm{K}]\} * 100$. High concentration of $\mathrm{Na}$ in irrigation water affects soil saturation, soil processes are related to ESP [8], as follows: at low ESP values (10-20\%) occurs a soil dispersion phenomenon associated to particles movement, and so far a reduction in the soil hydraulic conductivity; if ESP is between $15-20 \%$ there is tactoid formation and the particle double layer is being modified favouring repulsion; if $\mathrm{ESP}>25 \%$ tactoids are broken and an expansive process takes place; finally, if ESP $>50 \%$ the soil matrix undergoes a total rupture.

- Nitrite $\left(\mathrm{NO}_{2}\right)$ and nitrate $\left(\mathrm{NO}_{3}\right)$ - This is not an index but their presence indicates health of a soil. Concentration is usually low but it can be raised due to seepage or runoffs in farming lands. Maximum allowed concentration in drinking water is regulated to $\left[\mathrm{NO}_{3}\right]<10 \mathrm{ppm}$, while $\left[\mathrm{NO}_{2}\right]<0.05 \mathrm{ppm}$.

- Heavy metals - Special concerns are focused on lead and cadmium presence due to its high toxicity, regulated values in drinking water are $[\mathrm{Pb}]<0.01 \mathrm{ppm}$, and $[\mathrm{Cd}]<0.005 \mathrm{ppm}$.

\section{RESULTS AND DISCUSSION}

\subsection{Analytical results}

All analytical data were statistically analysed with minitab 1.7 software. In Table 2 are reported the minimum, mean, maximum and standard deviation; also, in the last two columns are included the normed values using the Mexican norm NOM-127 SSA1 for drinking water and irrigation standards.

As it can be observed parameter values which are out of the allowed range in the normativity, have been marked in bold. One group includes $\mathrm{pH}$, chloride $\left(\mathrm{C}_{1}\right)$, methyl orange alkalinity (AlkMO), parameters which even though their mean value is between the allowed range, the fact is that some samples were having values higher than the maximum allowed, what makes a point of concern. Another group can be formed with nitrite $\left(\mathrm{NO}_{2}\right)$, sodium $(\mathrm{Na})$, lead $(\mathrm{Pb})$ and cadmium $(\mathrm{Cd})$, these parameters are out of range in either irrigation or drinking use, and even the mean value is several times the maximum allowed concentration.

In Fig. 2 are plotted $\mathrm{pH}$ data, including lines for the low and high threshold values for either irrigation or drinking use. It can be observed that in reference to irrigation standards $(7-8$ in $\mathrm{pH}) 10 \%$ of the values are under the low limit, and $50 \%$ are above the upper limit, and only $40 \%$ of the samples satisfy the quality in $\mathrm{pH}$; otherwise using the drinking standards ( $\mathrm{pH}$ between $6.5-8.5$ ) it is observed that $3 \%$ of the samples are under the low limit, and $40 \%$ are above the upper limit, which means that only $57 \%$ of the sites could be used for human 
consumption, but this is not a decisive parameter since there are other parameters which are out of range.

\subsection{Water quality indexes}

In Fig. 3 it is presented data of the Sodium Accumulation Ratio (SAR), a parameter which define salinity risk, usually this parameter should be calculated using $\mathrm{Na}^{+}, \mathrm{Ca}^{2+}$ and $\mathrm{Mg}^{+2}$ concentrations; but in presence of alkalinity, this parameter should be adjusted (SARadj). Both parameters SAR and SARadj are presented in the same plot in order to make a comparison of how the presence of alkalinity modifies sample classification. So far, based on SAR calculations only 3 sites exhibit values between low and medium risk. But when the SARadj is calculated, most of the samples $(95 \%)$ are displaced to high salinity risk and the rest (5\%) are located barely below the high-risk threshold value.

Considering Exchangeable Sodium Percentage (ESP), it can be assessed information about possible structural changes in soil matrix due to the combined effects of $\mathrm{Na}, \mathrm{Ca}, \mathrm{Mg}$ and $\mathrm{K}$ concentrations. In Fig. 4 are presented ESP values, and threshold values defining transitions, the one at $10 \%$ stands for the transition from regular to dispersed soil condition, the one at $25 \%$ corresponds to transition from dispersed to expanded condition; and the one at $50 \%$ indicates change from expanded to broken matrix. As it can be observed ESP define that $26 \%$ of the sites are below the dispersion condition, $29 \%$ exhibit dispersion condition, $32 \%$ fall into the expansion risk, and $13 \%$ fall in a condition where rupture of the soil matrix can occur.

Table 2: Physicochemical parameters of San José Chiapa region.

\begin{tabular}{|l|r|r|r|r|r|r|}
\hline Parameter & Min & \multicolumn{1}{l|}{ Mean } & \multicolumn{1}{l|}{ Max } & Std-Dev & NOM 127-SSA1 & $\begin{array}{l}\text { Irrigation } \\
\text { standards }\end{array}$ \\
\hline $\mathrm{pH}$ & $\mathbf{6 . 2}$ & $\mathbf{8 . 0}$ & $\mathbf{1 0}$ & 0.9 & $6.5-8.5$ & $7.0-8.0$ \\
\hline $\mathrm{EC}, \mu \mathrm{s} \mathrm{cm}^{-1}$ & 33.4 & 916.0 & 6670 & 1051.0 & & \\
\hline $\mathrm{Cl}_{\mathrm{l}, \mathrm{ppm}}$ & $\mathbf{0}$ & $\mathbf{1 0 1 . 0}$ & $\mathbf{2 0 9 3}$ & 329.8 & 250.00 & 150.0 \\
\hline $\mathrm{AlkPH}, \mathrm{ppm}$ & 0 & 64.0 & 485 & 91.7 & & \\
\hline $\mathrm{AlkM}, \mathrm{ppm}$ & $\mathbf{2 9 . 1}$ & $\mathbf{3 7 7 . 0}$ & $\mathbf{1 0 7 1}$ & 326.0 & 400.00 & \\
\hline $\mathrm{HCa}, \mathrm{ppm}$ & 2.0 & 18.0 & 90 & 19.6 & & \\
\hline $\mathrm{TH}, \mathrm{ppm}$ & 5.0 & 21.0 & 60 & 17.2 & 500.00 & \\
\hline $\mathrm{SO}_{4}, \mathrm{ppm}$ & 0 & 50.0 & 460 & 78.9 & 400.00 & 250.0 \\
\hline $\mathrm{NO}_{2}, \mathrm{ppm}$ & $\mathbf{0}$ & $\mathbf{2 . 6}$ & $\mathbf{2 3}$ & 3.6 & 0.05 & \\
\hline $\mathrm{NO}_{3}, \mathrm{ppm}$ & 0 & 2.3 & 7.8 & 1.7 & 10.00 & \\
\hline $\mathrm{PO}_{4}, \mathrm{ppm}$ & 0 & 1.8 & 36 & 5.7 & & \\
\hline $\mathrm{F}, \mathrm{ppm}$ & 0 & 0.5 & 0.98 & 0.3 & 1.50 & 1.0 \\
\hline $\mathrm{Na}, \mathrm{ppm}$ & $\mathbf{3 . 7}$ & $\mathbf{6 3 4 . 0}$ & $\mathbf{1 4 4 6 2}$ & 2294.4 & 200.00 & \\
\hline $\mathrm{Ca}, \mathrm{ppm}$ & 6.6 & 69.0 & 608 & 98.68 & & \\
\hline $\mathrm{K}, \mathrm{ppm}$ & 2.9 & 42.0 & 300 & 66.44 & & \\
\hline $\mathrm{Fe}, \mathrm{ppm}$ & 0 & 0.6 & 2.15 & 0.75 & 0.30 & 5.0 \\
\hline $\mathrm{Mn}, \mathrm{ppm}$ & 0 & 0.8 & 6.04 & 1.19 & 0.15 & 0.2 \\
\hline $\mathrm{Pb}, \mathrm{ppm}$ & $\mathbf{0}$ & $\mathbf{0 . 2}$ & $\mathbf{0 . 6 1}$ & 0.21 & 0.01 & 0.5 \\
\hline $\mathrm{Cd}, \mathrm{ppm}$ & $\mathbf{0 . 0 1}$ & $\mathbf{0 . 3}$ & $\mathbf{1 . 0 5}$ & 0.363 & 0.005 & 0.1 \\
\hline $\mathrm{Mg}, \mathrm{ppm}$ & 1.32 & 284.0 & 2942 & 534.6 & & \\
\hline
\end{tabular}




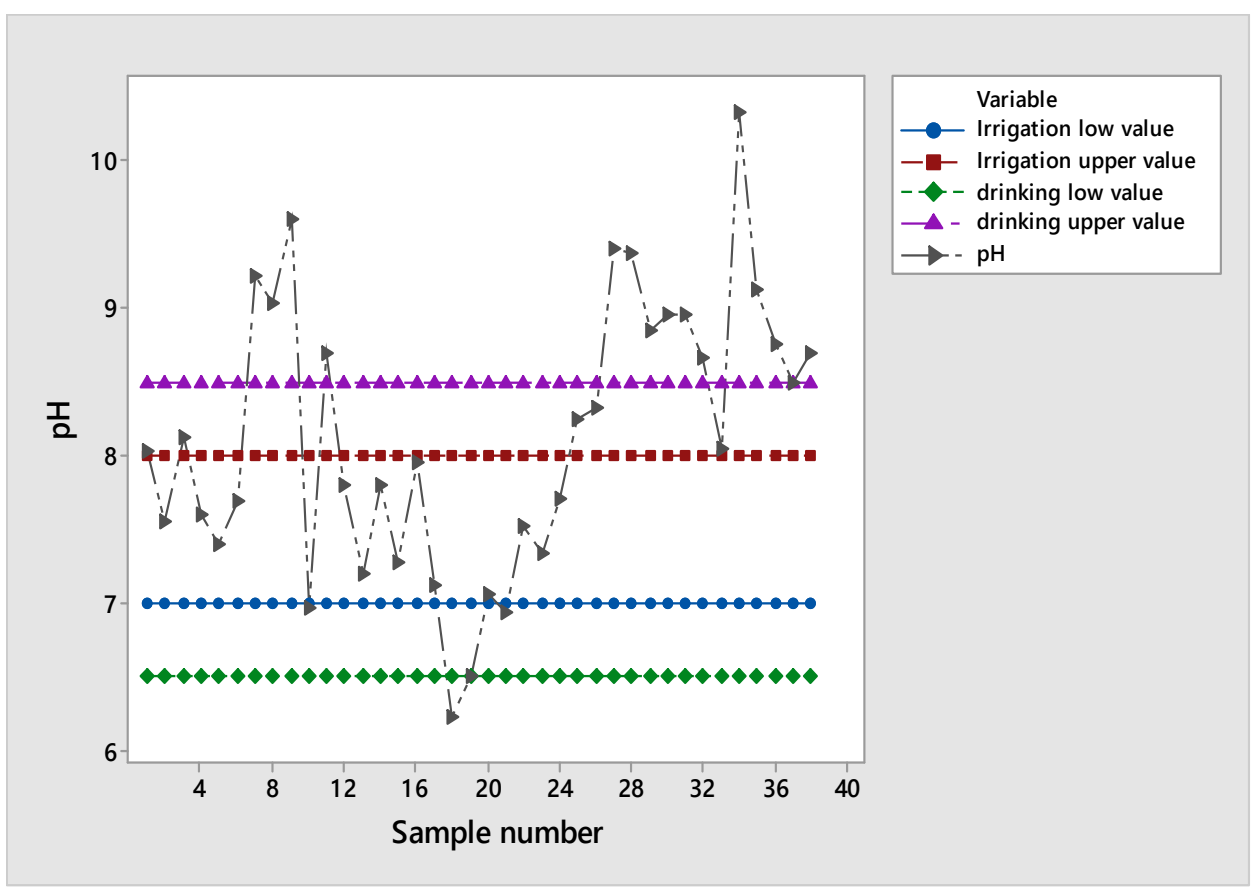

Figure 2: pH results of collected samples at the San José Chiapa region.

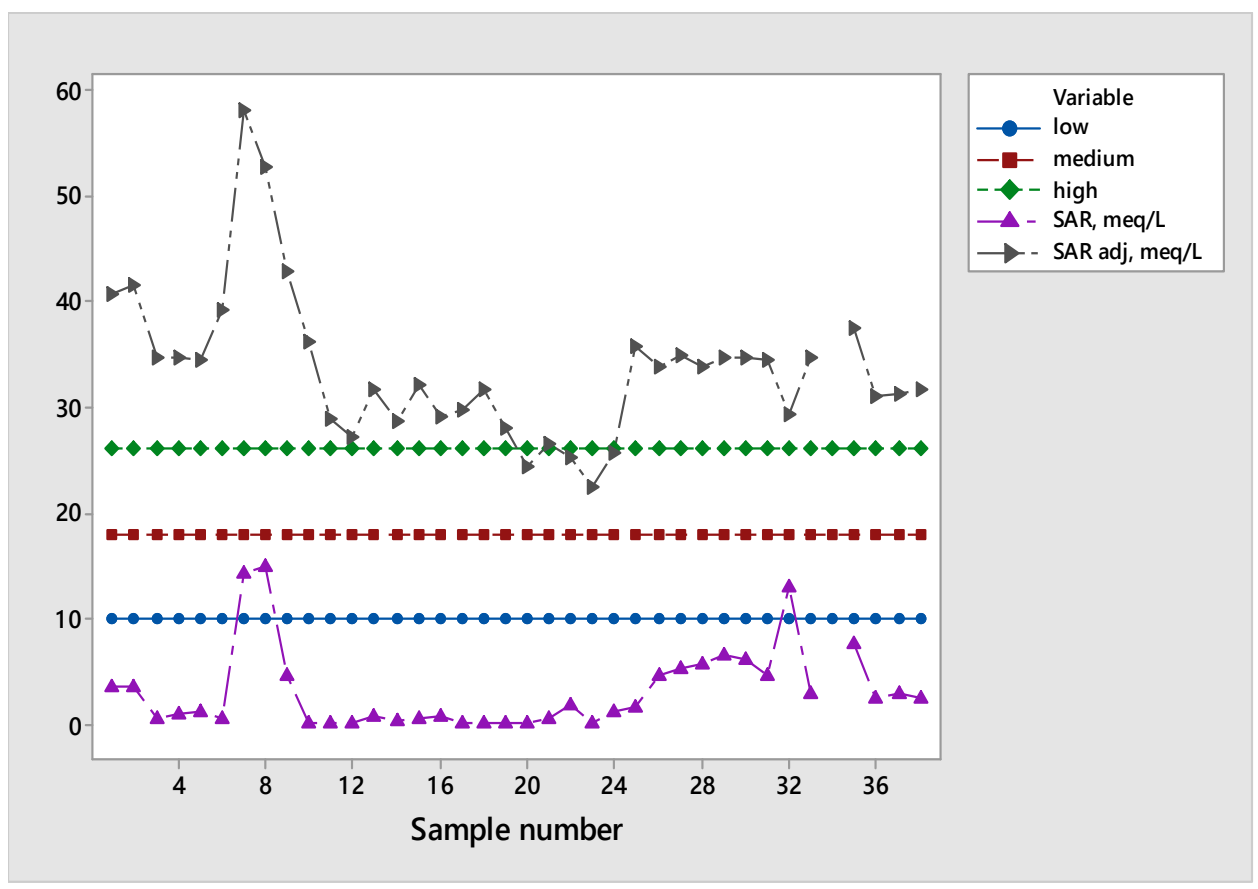

Figure 3: Salinity risk as function of Sodium Accumulation Rate (SAR). 


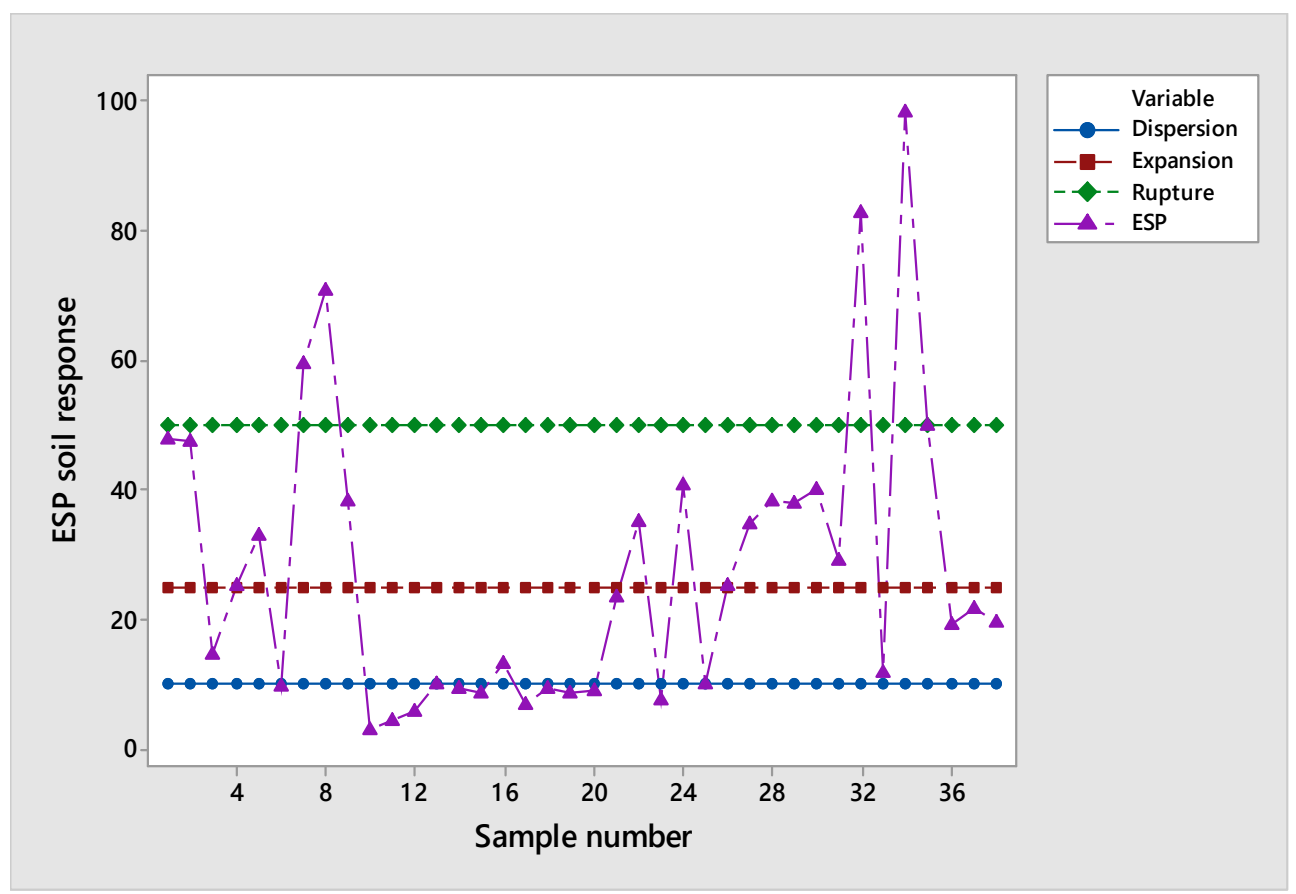

Figure 4: Effect of Exchangeable Sodium Percentage (ESP) onto soil matrix.

Values of Alkalimetric Coefficient or Scott Index (ACSI) which accounts for combined presence of $\mathrm{NaC}_{1}, \mathrm{Na}_{2} \mathrm{SO}_{4}$ and interactions between $\mathrm{Na}, \mathrm{C}_{1}$ and $\mathrm{SO}_{4}$ were obtained, according to this parameter $52 \%$ of the water samples fall into the good quality range (ACSI $>18$ ). Otherwise, $48 \%$ of water samples have ACSI $<6$ that corresponds to bad and mediocre quality and precisely in this $48 \%$ are included most of the samples collected at San Jose Chiapa, where the industry and urbanization has taken place. Otherwise, the samples collected at the nearby area classify as good. In Fig. 5 are shown the calculated values, for clarity values higher than $60 \%$ have been excluded, since they fall in the good quality range.

In Fig. 6 are shown the $\mathrm{NO}_{2}$ and $\mathrm{NO}_{3}$ concentrations, for these parameters the $\mathrm{NO}_{2}$ upper limit value is highly overcome, while the one for $\mathrm{NO}_{3}$ is only overcome in 1 sample. Usually $\mathrm{NO}_{3}$ concentration should be higher than $\mathrm{NO}_{2}$, and observing the plot is evident that concentrations of both are very similar, what can imply that nitrogen cycle has been modified in the whole region.

In Fig. 6 are shown the concentrations for $\mathrm{Pb}$ and $\mathrm{Cd}$, as it can be observed both metals exhibit concentrations that overcome the limit value in either drinking water or irrigation use. Since these metals are highly toxic for the human, those in charge of supplying drinking water should care for applying measures to eliminate $\mathrm{Pb}$ and $\mathrm{Cd}$ and provide a harmless drinking water. 


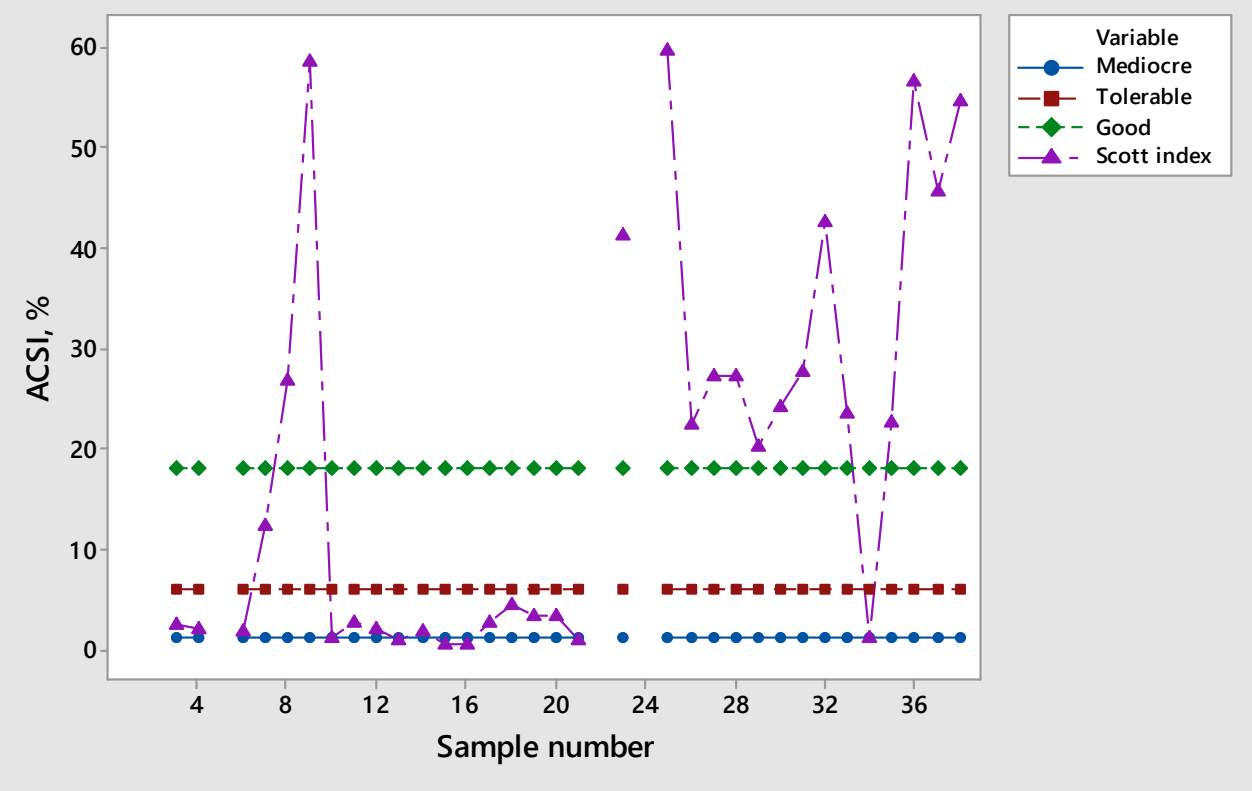

Figure 5: Alkalimetric coefficient Scott Index profiles.

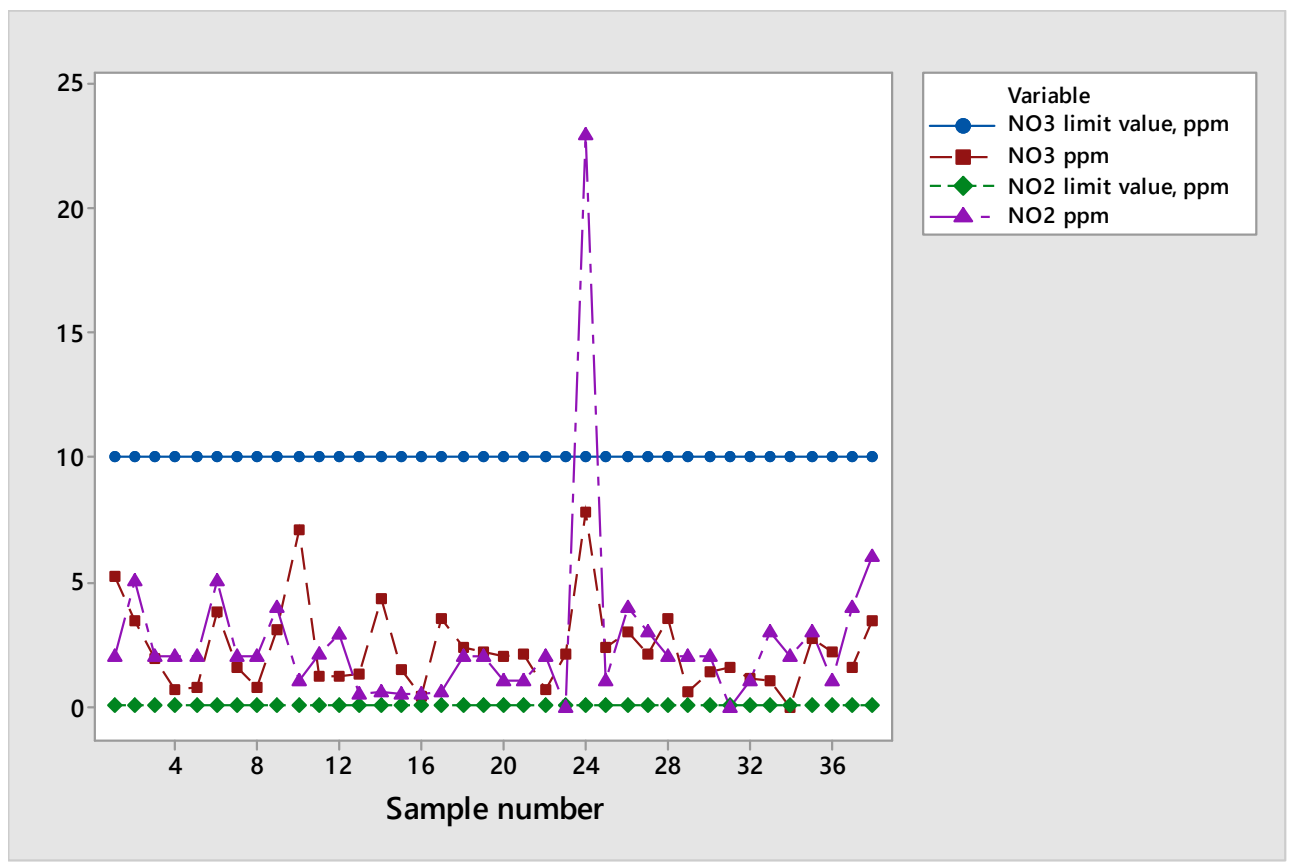

Figure 6: Nitrite $\left(\mathrm{NO}_{2}\right)$ and nitrate $\left(\mathrm{NO}_{3}\right)$ concentration profiles. 


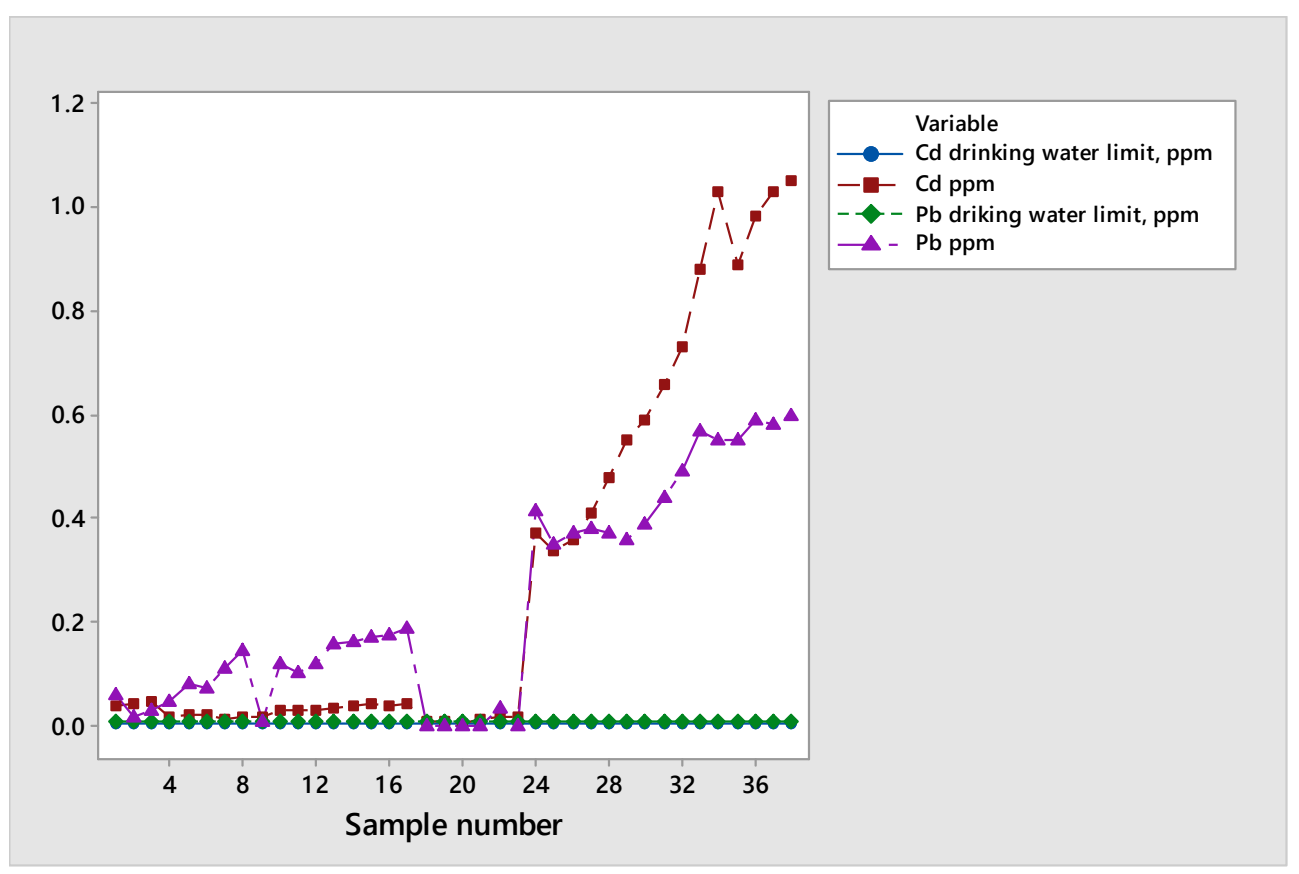

Figure 7: Lead and cadmium concentration profiles.

\subsection{Correlation statistical analysis}

The whole set of analytical results was analysed using Minitab Pearson's correlation criteria, in order to find how many possible parameter pairs are positive or negative correlated. The software provides the Pearson's correlation coefficient " $r$ ", which is a statistical measure of the strength of a linear relationship between paired data, values ranges between $-1.0<\mathrm{r}<1.0$; and according to Evans [9], strength of correlation in function of the absolute value of $\mathrm{r}$ can be described as: $0.00-0.19$ very weak, $0.20-0.39$ weak, $0.40-0.59$ moderate, $0.60-0.79$ strong, $0.80-1.0$ very strong. Also, software provides the "p" value which corresponds to the two tailed statistical significance of Pearson's correlation coefficient. In Fig. 7 are presented the statistical results; in this figure, coloured boxes corresponds to $\mathrm{r}$ value, and the clear one below is the p-value for the column-file pair.

There are 13 pairs exhibiting a very strong positive correlation $(0.8<\mathrm{r}<1.0$, with $\mathrm{p}=0.000)$ these pairs are: EC-Cl, EC-SO, EC-Na, $\mathrm{C}_{1}-\mathrm{SO}_{4}, \mathrm{C}_{\mathrm{l}}-\mathrm{Na}, \mathrm{CaH}-\mathrm{TH}, \mathrm{TH}-\mathrm{Fe}, \mathrm{TH}-\mathrm{Pb}$, TH-Cd, $\mathrm{SO}_{4}-\mathrm{Na}, \mathrm{K}-\mathrm{Pb}, \mathrm{K}-\mathrm{Cd}, \mathrm{Pb}-\mathrm{Cd}$. For this set of correlations, it should be point out that there is correlation of $\mathrm{EC}$ with $\mathrm{C}_{1}, \mathrm{SO}_{4}$ and $\mathrm{Na}$, but also between $\mathrm{C}_{1}$ with $\mathrm{SO}_{4}$ and $\mathrm{Na}$; additionally, between $\mathrm{SO}_{4}$ with $\mathrm{Na}$. It is worthy to point out that $\mathrm{EC}$ represents a salinity risk and $\mathrm{C}_{1}, \mathrm{SO}_{4}$ and $\mathrm{Na}$ concentrations define ACSI which is an indirect measure of the toxicity exerted by $\mathrm{NaC}_{1}$, Similar event take place for $\mathrm{TH}$ which correlates with $\mathrm{Fe}, \mathrm{Pb}$ and $\mathrm{Cd}$, but also $\mathrm{Pb}$ correlates with $\mathrm{Cd}$; since TH is accounted for SARadj, then this index could be considered an indirect measure of the toxicity due to heavy metals presence. 


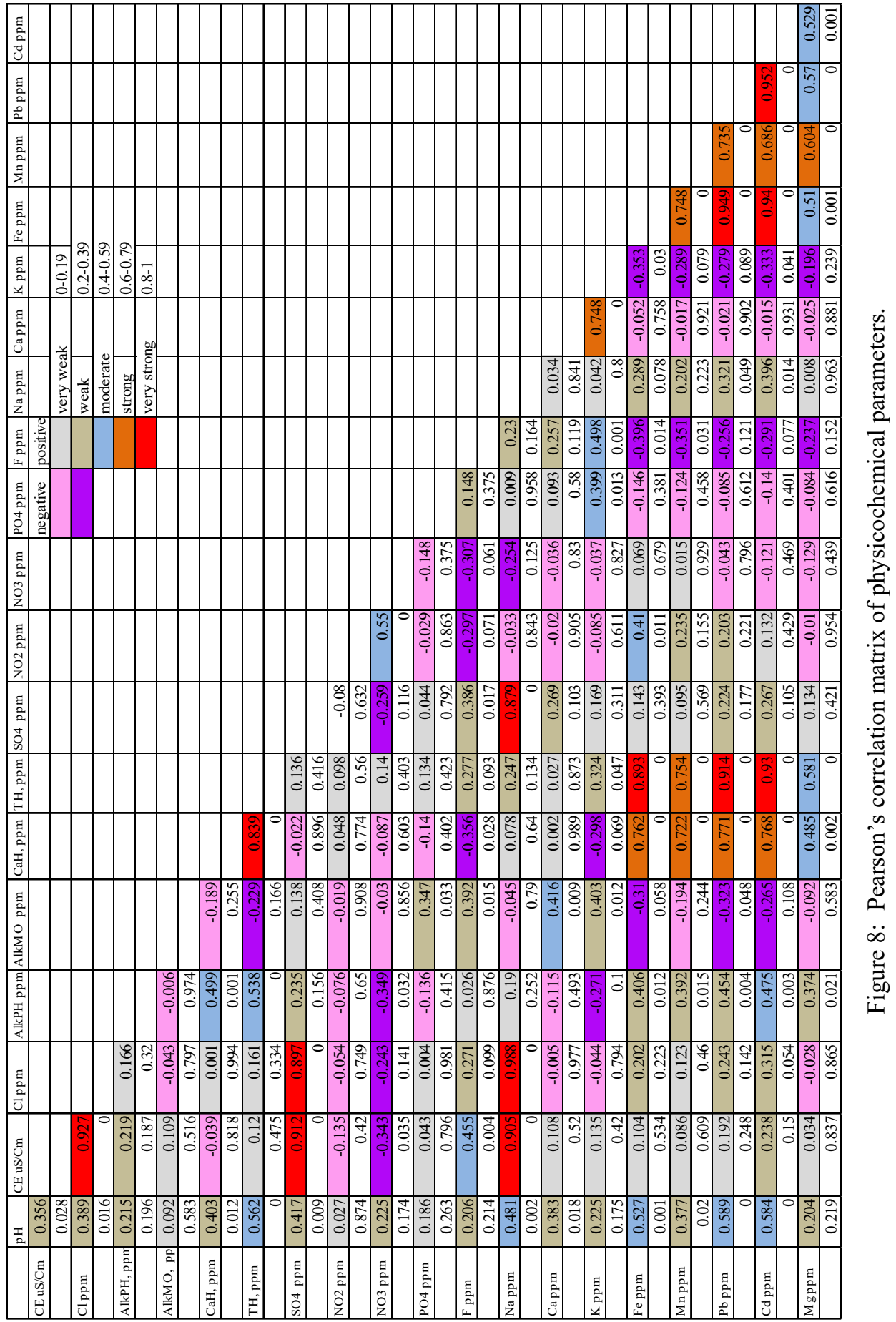


Also there are 10 pairs exhibiting a strong positive correlation $(0.6<\mathrm{r}<0.79, \mathrm{p}=0.000)$ these pairs are: $\mathrm{CaH}-\mathrm{Fe}, \mathrm{CaH}-\mathrm{Mn}, \mathrm{CaH}-\mathrm{Pb}, \mathrm{CaH}-\mathrm{Cd}$, TH-Mn, Ca-K, Fe-Mn, Mn-Pb, $\mathrm{Mn}-\mathrm{Cd}, \mathrm{Mn}-\mathrm{Mg}$. As it can be observed there is correlation of $\mathrm{Ca}$ with $\mathrm{Fe}, \mathrm{Mn}, \mathrm{Pb}, \mathrm{Cd}$, but also Fe correlates with $\mathrm{Mn}$; and $\mathrm{Mn}$ correlates with $\mathrm{Pb}, \mathrm{Cd}$ and $\mathrm{Mg}$.

In the moderate correlation range $(0.40<\mathrm{r}<0.59, \mathrm{p}<0.005)$ was found 19 pairs: $\mathrm{pH}-\mathrm{TH}$, pH-Na, pH-Fe, pH-Pb, pH-Cd, EC-F, AlkPh-CaH, AlkPH-TH, AlkPH-Cd, AlkMO-Ca, $\mathrm{CaH}-\mathrm{Mg}$, TH-Mg, $\mathrm{NO}_{2}-\mathrm{NO}_{3}, \mathrm{NO}_{2}-\mathrm{Fe}, \mathrm{PO}_{4}-\mathrm{K}, \mathrm{F}-\mathrm{K}, \mathrm{Fe}-\mathrm{Mg}-\mathrm{Pb}-\mathrm{Mg}, \mathrm{Cd}-\mathrm{Mg}$. For this group, it is worthy to point out that $\mathrm{pH}$ correlates with $\mathrm{TH}, \mathrm{Na}, \mathrm{Fe}, \mathrm{Pb}$ and $\mathrm{Cd}$, and these, except $\mathrm{Na}$, have a correlation with $\mathrm{Mg}$. These range accounts for parameter interactions which are considered to define the SAR and SARadj.

An unexpected event was found in the weak and very weak correlations data, it is surprising that ion pairs involved in the calculation of the ESP index exhibit a very weak correlation, these pairs are $\mathrm{Na}-\mathrm{Ca}, \mathrm{Na}-\mathrm{K}, \mathrm{Na}-\mathrm{Mg}, \mathrm{Ca}-\mathrm{Mg}$; and only the pair $\mathrm{Ca}-\mathrm{K}$ has a strong correlation.

\section{CONCLUSIONS}

Water resources at the region of San José Chiapa can be considered under threat because under the irrigation criteria $95 \%$ of SARadj values represent a high salinity risk, $48 \%$ of the ACSI values fall into a bad-mediocre category and most of these are in the San José Chiapa area; also ESP index indicates that $45 \%$ of the water samples represents a threat for soil matrix, since $32 \%$ of the samples represents an expansion risk, while $13 \%$ fall into rupture of the soil matrix.

It was detected an imbalance between $\mathrm{NO}_{3}$ and $\mathrm{NO}_{2}$ concentrations; and presence of heavy metals $\mathrm{Pb}$ and $\mathrm{Cd}$ in concentrations which already represent a threat for human health.

Statistical analysis allowed to find that there are some parameters $\left(\mathrm{pH}, \mathrm{C}_{\mathrm{l}}, \mathrm{AlkMO}\right)$ that exhibit out of range values but their mean value is in allowed range; otherwise there are parameters with high percentage of samples out of range in this group there are $\mathrm{NO}_{2}$ with $100 \%, \mathrm{~Pb}$ with $79 \%$, and $\mathrm{Cd}$ with $92 \%$.

From Pearson correlation analysis, it was found a very strong correlation $(0.8<\mathrm{r}<1.0)$ for 13 pairs, with a $p$ value of $0.000,10$ pairs of strong correlation $(0.6<r<0.79)$ also with $p=0.00$, and 19 pairs correlating in the moderate range $(0.40<\mathrm{r}<0.59)$, these pairs included most of the interactions accounted to estimate the ACSI, SAR and SARadj.

\section{REFERENCES}

[1] Instituto Nacional Para el Federalismo (INAFED), Los municipios del Estado de Puebla, de la enciclopedia de los municipios de México,1987.

[2] http://www.inafed.gob.mx/work/enciclopedia/EMM21puebla/municipios/21128a html. Accessed on: 30 Jan. 2015.

[3] Geoestadístico, M., Municipal 2010, Instituto Nacional de Geografía, Estadística e Informática version. 5.0, Online. http://www.inegi.org.mx/geo/contenidos/ geoestadistica/m_g_4.aspx.

[4] Organismo de Cuenca Balsas, Estadísticas del agua en la Cuenca del Río Balsas 2010, Comisión Nacional del Agua (CONAGUA), Secretaria del medio ambiente y Recursos Naturales, 2010.

[5] Can-Chulim, A., Ortega-Escobar, H.M., García-Calderón, N.E., Reyes-Ortigoza, A.L., González-Hernández, V.A. \& Flores, R.D., Origen y Calidad del agua subterránea en la cuenca oriental de México. Terra Lationoamericana, 29,(2), pp. 189-200, 2011. 
162 Water Resources Management IX

[6] Alvaro García, O., Criterios modernos para la evaluación de la calidad del agua para riego IAH, Online. http://www.ipni.net/publication/ia-lahp.nsf/0/ 6E4999FFE5F6B8F005257A920059B3B6/\$FILE/Art\%205.pdf.

[7] Aragües, R., Calidad agronómica de las aguas naturales, Canagua, 2001.

[8] NOM 127-SSA1-1994, Online. www.salud.gob.mx/unidades/cdi/nom/127ssa14.html.

[9] Secretaria de Medio Ambiente y Recursos Naturales, Ley federal de derechos: Disposiciones aplicables en materia de aguas nacionales, 2014.

[10] Evans, J.D., Straightforward statistics for the behavioral sciences, Pacific Grove, Brooks/Cole Publishing, 1996. 